\title{
The Foul and the Fragrant in Urban Exploration: Unpacking the Olfactory System of Leisure
}

\author{
Kevin Peter Bingham ${ }^{1}$
}

Received: 26 February 2019 / Accepted: 28 March 2019 / Published online: 24 April 2019

(C) The Author(s) 2019

\begin{abstract}
The world of leisure is a sensual reality, especially strong with the odours of what the French cultural historian Alain Corbin gave the name 'the foul and the fragrant', and their emotional affects. Yet, when it comes to unpacking leisure in a critical way the significance and complexity of the olfactory system of institutions and norms is largely overlooked in leisure studies. What is more, although smell is something that shapes our leisure and which we all instinctively recognise it buckles under the pressure of leisure studies obsession with the visual and the verbal. It is with this in mind that this paper, drawing on my own ethnographic research, offers a critical assessment of the ways in which the olfactory system emerges in a form of leisure known as urban exploration. One important way of defining urban exploration would be to say that its adherents have the need for authentic leisure experience which is, for the most part, unmediated by deodorisation. As well as being viewed as 'deviant', 'abnormal' or 'heterotopic' - and because of this - urban exploration takes advantage of the olfactory system as it is used to stimulate fears, pleasures and the broader imagination as a different 'taste' of life is experienced. Following an introductory episode that draws the reader into the world of a group of urban explorers that is oozing with the earthy smells of decay and the honey tang of piss, the first section of this paper employs the seminal work of Corbin to unpack how modernity, which never ceases to evolve and transform, continues to have a powerful influence on social space and the olfactory system. What emerges from this discussion, though, is the suggestion that it is the other side of modernity (the one that operates under a certain poetics of putrefaction) that is also the perfect breeding ground for inflaming both the magical and painful feelings of nostalgia by exploiting this olfactory system. Thereafter, using Tony Blackshaw's concept of the mundane and spectacular, the paper goes on to expand this idea by arguing that 'the foul and the fragrant' play a crucial role in the creation of heterotopic social space and its essential performativity.
\end{abstract}

Kevin Peter Bingham

K.P.Bingham@shu.ac.uk; kevin.peter.bingham@gmail.com

1 Faculty of Social Sciences and Humanities, Department of Psychology, Sociology and Politics, Sheffield Hallam University, Sheffield, UK 
Keywords Olfaction · Performativity · Heterotopic leisure $\cdot$ Poetics of putrefaction · Urban exploration

\section{Introduction}

In this article, I am interested in exploring the idea that setting our focus on the senses can be useful when it comes to unpacking and understanding 'deviant', 'abnormal' or 'heterotopic' forms of leisure. However, my attention lies specifically with the olfactory system because, as Andrew Sparkes (2009) and John Hockey (2006) argue, this sense has not been represented equally in the fields of ethnography and sport and exercise sciences. I would add that this same criticism can be extended to leisure studies, particularly where ethnographic work is concerned.

However, it is important to note from the offset that this article is not suggesting that leisure scholars who employ ethnographies fail to explore and unpack how social space is produced, or that they do not examine how 'radicalised' and 'deviant' identities are established and reinforced through processes of spatialisation. In fact, some leisure scholars have used ethnographies to explore under-theorised relationships between space and subcultures. For example, Lashua and Kelly (2008) have questioned how Aboriginal young people represent everyday urban space through hip-hop performances and practices. Likewise, Spracklen and Spracklen (2014) have raised the issue of how the subcultural authenticity of older, more established, post-punk Goths is being lost as space (specifically Whitby, the 'home of Dracula', which is now marketised as a 'spooky town') appears to evolve under the increasing visibility of mainstream tourism. And, more recently, Swain et al. (2018) have explored the links between the controversial leisure activity of khat-chewing and how users conceptualise spatial environments by creating a temporary and secretive sense of belongingness and cultural identity in liminal localities.

Yet, while the above-mentioned ethnographies capture the essence of themes such as rhythm, performativity and liminality vis-à-vis leisure space very well, what is conspicuously absent are detailed connections to the social constructions of smell and how they influence or impact upon the social production of space. In fact, with the exception of certain novelists and poets such as Marcel Proust, Charles Baudelaire and Aldous Huxley, and scholars such as Wacquant (2006), who apply olfactory symbolism to produce evocative atmospheres it might be argued that smell is the most undervalued of all the senses in Western literature and academic writing (Classen et al. 1994). This is perhaps not surprising, though, given that since the so-called 'postmodern' turn many of the key theorists we often turn to to make sense of present modernity, such as Baudrillard, Bauman and Lyotard, deal with media saturation, consumption and the visual. In other words, it is manifest that visual representation dominates as the leading form of perception in the twenty-first century (Low 2009; Howes 2005; Foucault 1970; Berger 1972). There is, as Richard Rorty (1979) argues, a certain charm about the eye and a pervasive assumption exists in that we imagine it mirrors our nature and culture.

There is also the point that there is perhaps a certain degree of bias involved when it comes to dealing with some of the senses. This point is emphasised by Jacques Derrida (1993) as he argues that Western tradition is shaped by sets of binaries where one is always prioritised over the other. What this could mean is that the vocabulary used to 
describe what our sense of smell detects is considerably more limited than the voluminous language employed to depict the visual (Synnott 1991). As Diane Ackerman notes, when we attempt to describe the features of an odour we tend to do it metaphorically, using words 'such as smoky, sulphurous, floral, fruity, sweet', that are used to describe other things: smoke, sulphur, flowers, fruit and sugar (1995: 7). Ackerman goes on to draw our attention to the fact that smells themselves are never really described; what is actually communicated when we smell something are our feelings and whether we find the scent 'disgusting, intoxicating, sickening, pleasurable, delightful, pulse-revving, hypnotic or revolting' (ibid: 7). Nevertheless, critics might argue that what Ackerman overlooks is the basic point that words must be used to depict smells because there is no other way of describing them in detail - this is simply the best way! The real issue when it comes to dealing with the olfactory system, then, can be found nestled in the work of Immanuel Kant.

According to Kant (1974) and many of his contemporaries, senses can be divided into lower and higher categories. Kant draws attention first to 'lower' subjective senses such as gustus (taste), tactus (touch) and olfactus (smell) where any associated pleasures and displeasures merely register impressions and only perform or serve any usefulness when objects are within close proximity. They are, in other words, viewed as being somewhat primitive and connected with savage-like behaviours (Classen et al. 1994). 'Higher' senses on the other hand, tisus (sight) and auditus (hearing), are interpreted by Kant as being the most objective and are therefore viewed as being superior because they are empirical, function the farthest away from an object, and are well-suited to the free play of the human imagination (Kant 1974). Rather than advance such claims any further, then, this article sets out to challenge the implied primacy of the olfactory system which appears, consciously or not, to have permeated the mindsets of many leisure scholars.

While recognising the importance of those ostensible 'higher' senses to ethnographic enquiry in leisure studies, I want to note that serious limitations and takenfor-granted assumptions are likely to materialise if 'lower' senses such as the olfactory system go on being disregarded or overlooked. A consequence of adopting an inequitable Kantian stance is that our understandings and interpretations of leisure, particularly those that find themselves labelled as 'deviant', 'abnormal' or 'heterotopic' where extant research is also often inadequate (Rojek 2000), are at risk of being limited and misconceived. As Classen, Howes and Synnott argue, rather than being a simple psychological or biological phenomenon:

'... smell is cultural, hence a social and historical phenomenon. Odours are invested with cultural values and employed by societies as a means of and model for defining and interacting with the world. The intimate, emotionally charged nature of the olfactory experience ensures that such value-coded odours are interiorized by the members of society in a deeply personal way. The study of the cultural history of smell is, therefore, in a very real sense, an investigation into the essence of human culture' (1994: 3).

Therefore, in a bid to acknowledge olfaction, and build on Classen, Howes and Synnott's (ibid) suggestion that more should be done to bring odour into social and intellectual discourse in leisure studies, I aim to explore its significance vis-à-vis a 
group of urban explorers. ${ }^{1}$ To approach this task, I first take into account the historical influence of smell vis-à-vis the modern era and take note of how it continues to have an impact on social space in a contemporary leisure world. What this means is that I take into account Bauman's (1993a) argument that it was perhaps modernity that brought with it a noticeable compulsive desire to eradicate foul smells by establishing designated spaces of control. In Bauman's words, 'modernity declared war on smells. Scents have no room in the shiny temple of perfect order modernity set out to erect' (ibid: 24).

Next, I go on to expound an aspect of olfaction that seems to evade discussion in any serious depth in the field of leisure studies; I draw out the importance of smell in the way it contributes to a collective task of interpretation between a group of urban explorers. What this means is that this interpretation accepts there are two levels to olfaction. Taking the scent of pigeon faeces as an example as it is part and parcel of urban exploration, it can have two effects. Many people might make the straightforward claim, 'I can smell shit', as the musty fug of dried pigeon droppings invades their nasal cavities. Others, however, who are more in touch with abandonment and decay as a site of leisure might say, 'I can smell nostalgia' or 'I can smell fear', as odour-evoked memories and imaginings become emotionally potent. In other words, there is another level, one that comprises all of those all-too-familiar scents of the damp, mysteriously homely aroma of abandonment, that bursts at the seams with fragrant romantic and quixotic sensibilities insofar as they conjure both the magical and the painful feelings of nostalgia and fear (Blackshaw 2013).

However, before any discussion commences what follows first is a short episode that has been drawn from my own ethnographic research that was conducted while completing my doctoral studies. My study was centred around a group of urban explorers who are known collectively as WildBoyz. ${ }^{2}$

\section{The Siege: Breaching the Parapet}

It was two minutes past midnight and we were speeding down the motorway towards Dover Ferry Terminus. The aim was to catch a late-night ferry over to France where we would track down and explore an abandoned castle that was originally constructed in the thirteenth century. With some 'bangin' tuneage', plenty of beer and several boxes of chicken nuggets, 'the craic' as we like to call it was 'fuckin' epic' and the mood in the car was especially jovial. The magic of the world of WildBoyz was back in full swing and, just as we manage to convince ourselves every other time we succeed in recreating it, our sense of belonging and authenticity never felt more powerful.

Nonetheless, the greasy smell of chicken engulfed us, like an invisible fog that seemed to mingle with the strong oniony tang of body odour, the eggy stench of farts, and the fruity aromas of cheap beer which, after being shaken too vigorously, was frothing from the tops of our cans. Husky added his own unique contribution to the strange stench that was steadily forming inside the car. First of all, to borrow MKD's

\footnotetext{
${ }^{1}$ Urban explorers can be defined briefly as individuals who explore human-made structures and environments that are generally abandoned or hidden from the public eye.

${ }^{2}$ WildBoyz are a group of 'urbexers' whose name was inspired, parodically, by the Duran Duran song Wild Boys. 'The Boyz', as they exist today, are known as: Ford Mayhem, Meek-Kune-Do, Rizla Rider, The Hurricane, Box, Husky and Soul.
} 
description, 'his feet fuckin' stink'; if you asked any of 'the Boyz' to elaborate they would tell you that they seem to produce an egregious, rotting, sort of pong. Second, since our last quick stop-off at services he'd decided to busy himself by unpacking his 'herbal remedy kit'. Translated, this means he'd 'crack'd out' his grinder to roll a fresh spliff. This caused a 'skunky' sort of smell to mingle with the existing aromas.

Perhaps it was the weed, the smell of fried chicken that seemed sticky and irremovable, the build-up of bodily gases or the rankness of Husky's boots, but it didn't take long until the smell inside the car gradually became more noticeable, to the point that it started to affect our mood. To remedy the problem MKD decided to employ the usual tactic of emptying a canister of Lynx into the mix. The sour tang of deodorant erupted from the can, forming a whiteish cloud that made it extremely difficult to breathe. Once it settled a little, however, 'the Boyz' seemed satisfied that the problem was resolved. As the scent settled into something that was neither quite pleasant or unpleasant, only strangely familiar, 'the craic' quickly sprang back to life. It was enough to convince 'the Boyz' that the air was purified and fresher. Feeling his mood lift, MKD yelled, 'Yes, boys. That's betta', like. It still fuckin' stinks, but it smells cleana' in here. Like in the gym. Ya know, like the changin' room. Sort of a little bit sweaty but sort-a cleana' as well.' For a while, 'the Boyz' seemed to agree with him. Nevertheless, getting out of the car while waiting to board the ferry meant that the foul smells seemed to reignite when we all climbed back in, and this forced us to repeat the deodorising process all over again.

The overall fragrance of our adventure didn't improve much the next day. After driving for a further seven uncomfortably sweaty hours, with very little time set aside for stopping, we finally reached the castle but quickly discovered we had to cross several muddy fields and a moat to access it. In terms of the smell, the fields weren't so bad. A little earthy, tinged ever so slightly with the scent of ageing fertiliser. However, while we were standing beside the moat, staring at the castle across the cold, olivecoloured, water, 'the Boyz' started to doubt whether we should bother to explore it or not. A large dead fish lurked just beneath the surface to the right of us and a mephitic, sulphuric sort of smell, emanated from the water. For a while, nominating who should swim across first caused an intense debate, until Mayhem finally stepped up and announced he was going to do it:

Mayhem: [Stripping his clothes off]. How much do you like urbex?

Husky: Not this much.

[Laughter].

Mayhem: Fuck sake. I'm down to me shreddies.

Husky: We've come this far, we av' to do it.

Me: I don't see you takin' yer kegs off.

MKD: Yeah man. I'll do it, just not goin' first.

Mayhem: I am, man. I'm gettin' fuckin' nake'd 'ere.

Husky: Actually, man, I think you're gonna' catch the fuckin' plague.

MKD: That Black Death shit?

Husky: Yeah, dude. That was about when this castle was built.

Mayhem: Don't tell me that, man. That's bullshit. Right?

Soul: Be good for the immune system, mate. 
[Several moments later...].

Mayhem: Awww, man. Noo. Nooo. Fuck. Fuck. Here it goes. Shit, boys! What if

I catch the bloody plague? [He begins to wade into the water].

[Laugher]

MKD: Oh, he's doin' it! Fuckin' hell, like.

[Laughter].

Mayhem: Oh my god. It's so cold... [Wades in further until he's beyond 'balls deep'].

Soul: Yes, fam!

Mayhem. Okay, fuck this! The smell is getting worse. I'm fuckin' bailin'! Any of yous bring any deodorant with yers?

Everyone: [General mumbling]. No.

Mayhem: Cunts.

An hour or so later, following two more failed attempts by Soul and Husky to swim across the moat, we had almost resigned to the fact that we had been defeated. However, as we ambled back towards our camping spot we happened to stumble across a couple of boats and a single paddle lying near a lake that we hadn't noticed earlier. So, in true spirit of urban exploration and being 'deviant', we decided to borrow one of them and, therefore, soon found ourselves paddling frantically across the stagnant water of the moat.

By now the sun had set, so plunged in darkness we could no longer peer into the filth below us. This meant that now it was purely the occasional showers of polluted water from my erratic paddling, and the oozing stench of decay rising from the moat itself, that kept our fear of falling in alive. Despite the fetidity and chaos, though, there was something incredibly exciting and familiar about the whole experience. Even with large overarching willow branches snagging at our clothing, and the threat that they might capsize us as they caused the unsteady boat to list violently several times, the great castle still teased us on. Before long we could smell it! It was luring us in with an alltoo-familiar scent - the damp, mysteriously homely aroma of abandonment. 'Do you smell that? There it is! Fuckin' beast', yelled Mayhem. Suddenly, Husky, Mayhem and Soul launched into an excited discussion together about decay. Just ahead we could see the crumbling stonework of the castle. It was fucking enormous and, knowing we were about to crash the boat against a set of dilapidated stairs, we were alive with excitement.

The warm scent of decaying stonework and rotting vegetation greeted us as we entered the castle. We'd all managed to clamber out of the boat unscathed and now found ourselves in a large room - presumably the former great hall - which was overflowing with large trees and bushes. After gazing at the magnificently curious sight all around us for a while and taking a few snaps, we made our way excitedly towards a dark corridor directly ahead of us. The thrill and sense that something spectacular was all around us was now immediate. Animated and craving more, we cracked on, stopping only to savour the strong aromas of the rotten wooden beams that had collapsed from the ceiling directly above us. Our eyes widened as the beautiful smell stirred in our nostrils. The steps we'd followed inside the tower to our right gradually became more deteriorated the further up we went, until finally we reached a gaping hole at the very top of the tower. In that moment, looking out towards a parallel turret that was brightly lit by thousands of bright stars as the wind reignited the 
powerful smells of dust and rotting vegetation from the keep below, the experience felt ineffable. As Soul tried to put it, the moment presented 'something that's beyond fucking incredible, especially with its raw smell that's totally unconditioned.'

After 'mooching' around the castle we withdrew to our camping spot, an abandoned farmhouse set on the border of the large grounds. We'd parked up here initially and, having smelt the all-too-familiar scent of staleness and decay oozing from its orifices, we'd decided it would be a good place to set up camp. Now, entering the building felt like returning somewhere homely. We'd set up our camp-beds and hammocks earlier and now the damp smell of the stonework mixed perfectly with the beefy aroma of our cooking. The immediate plan was to get a roaring fire going in the crumbling fireplace and crack a few bevvies open. It didn't take long to start the fire, and for the heavy, intoxicating smell of smoke to swirl lazily throughout the building. It wasn't long either before a bottle of blended whisky emerged from one of the rucksacks. Once it was opened, the slightly sweet oaky smell of the whisky mixed pleasantly with the prickly scent of dust that was ingrained in the farmhouse. The fire continued to crack and burst for the rest of the evening, constantly refuelling the beautiful, homely aromas of the building for the next few hours.

The journey home was a lot less spectacular than the previous day had been. It began with an early four o'clock rise inside the farmhouse that had lost its warm sense of homeliness and transformed into something cold and dirty. The building now emitted a sour smell of stale piss that seemed to mix unpleasantly with the livelier tangy odour of human grease. We then travelled an uncomfortable seven hours to reach the midday ferry home. As Mayhem put it, 'we were wreck'd', and only just made it on time. By the time Mayhem stopped the car sharply on the ferry deck, narrowly missing the freshly waxed bumper of a silver Merc in front, we couldn't wait to get out and stretch our legs. One by one we clambered out of Mayhem's soiled car, emerging onto a large internal deck that smelt wonderful. Intriguingly, the intoxicating scent of petrol instantly reinvigorated our mood and 'the craic' suddenly seemed to spring back to life for a moment as we made our way towards a staircase that would take us upstairs.

Up on the main passenger deck, surrounded by the strong, satisfyingly rich smells of coffee and thick gravy, we found ourselves a table and collapsed onto the chairs around it. We were 'absolutely fuck'd' and, wanting everyone around us to know it, we put on an exaggerated performance. There was something cool, or 'badass' to borrow Husky's way of describing it, about walking through the ship and trailing the smells of decay and abandonment through the throng of clean, everyday people. Husky sat with his mud-caked boots up on one of the chairs opposite him, and Soul dropped his filthy camera bag onto the white table top. He sat, sprawled across a chair in his sweat-stained t-shirt, with both arms hanging limply over its sides. Mayhem 'cabbaged out' across a cushioned bench, coating it in grey dust that fell from his crusty jacket and trousers, and MKD began cleaning one of his mud-caked boots against a chair leg.

However, there was only so long we could convince ourselves our performance was 'cool'. As the journey continued, it didn't take long for us to notice that other passengers were avoiding us, giving us a wide berth as the tables closest to us remained unoccupied despite the ferry being busy. We could feel eyes watching us, forming views and opinions about the dishevelled, abhorrent, appearance of our collective. A sense of anxiety started to grow. The fact that we fucking stank was starting to bother us. It was Soul, though, who finally put an end to our performance when he decided to 
complain that our boots all reeked of 'cow shit', and that the smell was 'pretty intense'. With that knowledge firmly lodged in our minds, Mayhem, MKD and myself decided to find the nearest toilet to clean ourselves up a little and, according to Mayhem, look more 'socially acceptable, like propa' consumers again.' As MKD put it, describing reasonably well how we were all feeling at the time, 'I feel really outta place, like. People'll think we homeless or some fuckin' scummy dole munchas.'

\section{3 'The Olfactory Revolution'}

The modern human relationship with odour is long and complex and it comprises many confusing myths, taboos and, above all, a deeply rooted fear of the invisible. With this in mind, although he centres his attention on the perception of odour in France from the 1700s to the 'Pasteurian Revolution' of the late 1900s, Alain Corbin is perhaps the best chronicler of the history of olfaction as his seminal book, The Foul and the Fragrant, traces the course of our tempestuous relationship with odour and it draws out three significant modes of behaviour. The following section of this paper unpacks these behaviours vis-à-vis our current stage of modernity and a small group of urban explorers to reveal more about the ephemeral and contradictory world we presently find ourselves in (Bauman 2000). As the reader will observe, what is uncovered is that our attitudes towards odour, and the strategies we adopt to eliminate bad smells and incite pleasurable ones, remain as paradoxical as ever. In other words, there are echoes here of Foucault's (1970) claim that the concept of the rational individual - who is capable of rejecting difference and inaugurating a universal identity - is false, and likely only to cause us to take a step backwards in our interpretations of contemporary society.

\subsection{Purification and Deodorization}

To begin, it is important to consider Bauman's (1993a) suggestion that modernity, particularly in its early stages of advancement and among the elite, brought with it a frantic urge to purify the surrounding air. Such thinking carries a theological basis as religion has functioned as a coping strategy that has allowed individuals to distance themselves from the suffering of the world through purification strategies for thousands of years (Martin and Triplett 2013). However, while civilization has progressed and the need for religion grown weaker a broader anal eroticism for the need for purity, in the form of order and cleanliness, has evolved (Freud 1994). With this in mind, the aim in the preliminary stages of modernity, as Corbin (1986) points out, was to disguise everything unnatural and all accumulations of foreign particles; focus at a surface-level was set on the rejection of everything lecherous, dirty and corrupt in order to produce a purer, tidier world. Yet, irrespective of the ceaseless desire to cleanse the air, even today, the artificiality and unfeasibility of such a project in modernity is conspicuous, once we realise that any modern project that endeavours to create something pure will always be undermined by a stench that remains stubbornly unregulated and beyond our control (Bauman 1989). Seemingly aware of this, it is interesting then that 'the Boyz' tactics to battle contaminated air have not evolved far beyond 
those surface-level strategies that were originally employed across the seventeenth and eighteenth centuries.

Analogous to individuals in the late 1700s, 'the Boyz' solution to the fierce stench contaminating the car was to make it disappear temporarily by masking it with a stronger fragrance: the vulgar and, in their opinion, ostensibly fresh changing-room tang of Lynx. The overall effectiveness of this effort to eliminate the foul smell of five males is moot. On the one level, 'the Boyz' managed to convince themselves that the powerfully sharp, zingy, notes of deodorant to some extent purified the environment. On the other, the Lynx merely amalgamated with the dirtily-sweet sweaty odour that seemed to cling to everyone and everything in the car. In any event, the new fragrance seemed to have the desired, albeit shortlived, effect of producing an agreeable smell and this completely transformed the mood to something that felt more cheerful and positive. What this reinforces, as Corbin (1986) points out, is that not only is the sense of smell an emotionally charged one, it is also something that is a possible source of immediate gratification and therefore powerful obsession, even if it is only temporarily. It might be argued, then, that olfaction immediately exposes one of the key features of our present condition of modernity, that surface-level strategies for tackling odours are convenient not so much for belief in purification purposes anymore but for the 'quick-fix' solution they offer that is more in tune with the immediacy and swiftness of present modernity.

As Bauman (2000) points out, speed has become the most useful asset in present modernity (a period defined by instantaneity, addiction, ambition, impatience and consumption) as most sources of gratification, not least because they are ephemeral, must be achieved within the shortest duration of time. In view of this, it seems that when it comes to combatting olfactic corruption in the atmosphere and restoring the elasticity of the air, the theory that strong aromatics will rapidly and effectively mask a foetid stench prevails. However, unlike attitudes of the past, which were guided by the pseudo-scientific advice that aromatics provided protection from the smells of excrement and decay (Corbin 1986), the contemporary opinion is supported by what Paul Virilio (1977 [2006]) has labelled the 'dromocratic revolution'. 3 Notwithstanding the fact that he disagrees with the Marxist idea that modernity is a result of economic transformation in favour of military influence, Virilio is effective in outlining how our reliance on feudal-era fortifications has transformed into a war of movement that has dramatically altered the pace of life in present modernity. The 'dromocratic revolution', then, goes some way towards reflecting our accelerated way of life and encourages us to think about the 'quick-fix' social, psychological and cultural impact it has had on our leisure worlds.

In terms of leisure, the acceleration of life has made more opportunities and choices available but, as we witnessed with 'the Boyz' in their effort to control their own odour, it also means that our experiences and ways of thinking are becoming increasingly numbed, mechanised and empty (Rojek 1995). However, to avoid sounding altogether nihilistic, it is important to recall the later work of Georg Simmel which encourages us

\footnotetext{
${ }^{3}$ The term dromology, which derives from the Latin word dromos (race), is a term coined by Paul Virilio to explain the importance of speed and acceleration in present-day societies.
} 
to take note that what has been suggested so far only reflects one side of the coin. According to Simmel (2014 [1890]), modernity is best understood as something that causes a 'twin sickness'. On the one hand, modernity fosters anaesthesia by steering people into a 'quick-fix' state that induces the loss of awareness and sensation, but it is incapable of causing amnesia or paralysis because sensory experiences are still something we continue to desire in our leisure (ibid). As Simmel points out, in actual fact it is an overstimulation of sensory experiences in modernity that often causes people to crave the 'sensuously rare, peculiar and delicate to expand the scope of sensibility' (2014 [1890]: 4). What this means is that beyond the effects of anaesthesia we should not overlook, especially among urban explorers, that there can be overwhelming impulses that compel us to seek out certain sensations, including odours because there are some that trigger hyperaesthesia (an excessive sensitivity). More on this point will be discussed in the latter part of this paper.

\subsection{Disinfection}

The second important issue to consider is modernity's progressive drive to target and disinfect sources of foul odour, as opposed to merely masking them (Corbin 1986). If we reflect on our human relationship with odour once again it is apparent, especially during the 1940s when the Beveridge Plan emerged, that hygiene and health suddenly became an important concern across Europe (Foucault 2004). What is crucial, though, as 'the Boyz' reveal in the short episode above is that our obsession for the modern life strategy of being hygiene-conscious still seems to thrive in the twenty-first century. However, as I will go on to explicate, a paradox transpires when we begin to reflect on this idea, a paradox which reveals more about the fluid type of world and society in which people seek out different and increasingly unique forms of leisure.

For each of 'the Boyz', life should be a healthy one. Hygiene, described most appositely by Bauman as being 'the modern technology of keeping disease at bay' (1992: 155), appears to be at the forefront of their imaginations, and it is often an unpleasant odour that keeps it firmly rooted in their minds. As they demonstrated while contemplating whether they should swim across the castle's moat that was oozing with the stench of staleness and decomposition, bodily contact seemed both dangerous and unpleasant. Husky reinforced this point further when he revealed his uneasiness about the plague apparently existing throughout the medieval period, and his fear that the water might somehow still be infectious. In the minds of 'the Boyz' a dark abyss lay ahead and contained within it was the stench of disease and the unknown. It is likely, then, that their initial plan was set to fail from the very beginning, despite Mayhem's best efforts and going 'balls-deep' in the cold filth.

Like most people, 'the Boyz' have lived in a world where mortality has been deconstructed and dirty operations such as waste disposal, cemeteries and sewage works have become isolated spaces set apart from the rest of society behind their high walls, gates and palisade fences (Foucault 2003; Corbin 1986). This of course connects well with Norbert Elias' (1994) concept of the 'civilising process', which suggests that modernity, in its solid and formative stage, has become more cautious and focused on improving standards and etiquette which entails the prevention of undesirable or destructive behaviours. As Elias suggests, people have been pushed in a direction that causes them to feel such things as revulsion, ignominy and remorse if they witness or 
feel over-expressive emotions (particularly certain smells) that have been deemed inappropriate outside certain controlled environments. What this means is that signs and causes of mortality are challenged by our continued efforts to avoid or overcome them and they instil a certain degree of paranoia (Bauman 1992). To single one of 'the Boyz' out specifically, Mayhem revealed this behaviour and mindset two days after our trip when he reported to the rest of the group his concern about a rash that had formed across his legs and back. He was absolutely convinced he had contracted it from the moat. By his reasoning: '[it] was dirty as fuck and smelled like absolute shit, guys. It's the only thing I can think that cud av' caused it... Jesus christ, that smell, man. There was a dead fish in it for fuck's sake!'

Nonetheless, and notwithstanding the significance of the argument above, a paradox emerges in the sense that odour also has a contrasting behavioural influence on 'the Boyz'. Essentially, what I have in mind here is Blackshaw's (2017a) point that one of the major accomplishments of present modernity has been its ability to transform life from being exclusively regimented and sanitary into something that also allows individuals to forgo their fears and anxieties in the hope that dreams and hopes can be lived out. In this sense, the other side to olfaction is that beyond the seemingly resistant layers of the foul and foetid there can be something magical about it, insofar as our choices of leisure, such as urban exploration, often encompass it as part of the overall enchantment. Implicit to this understanding is Bauman's sociology because it teaches us that we are no longer dealing with 'solid' modernity. As Bauman (2007a) outlines, we are dealing with something more fluid, and with individualised consumers who are not so much concerned about finding an essential identity or experience as they are about experimenting with the task of inventing and reinventing them.

As revealed in the episode above, 'the Boyz' successfully manage to push aside their concern for disease, disorder and chaos when an opportunity to perform is found. After crossing the malodourous pool of water, 'the Boyz' truly stepped into their leisure world where they each share a sense of mutual passion, purpose and pleasure. They clambered out of the boat onto the broken stone steps of a crumbling castle where they were welcomed by the all-too-familiar steady hum of decay. A resoundingly unpleasant, yet strangely nostalgic, humid odour subtly tinged with the scent of rotting vegetation immediately struck their nostrils. All of a sudden, 'the Boyz' were back where they belonged, as dedicated and resilient wanderers of wasteland and abandonment. As Mayhem pointed out a few days after we had returned home, which, looking at the faces of the others at the time, seemed to confirm what they were all thinking: 'No-one else I know is like us, man. Like, seeking out history like this and somehow hackin' the smell of crap... It's strange how the smell of shit can lure us, like, and we like it. What the fuck!'

It is the experience of performativity, then, that is key to understanding 'the Boyz' enigmatic relationship with foul and foetid odours. Through the medium of urban exploration, 'the Boyz' use strange, unfamiliar, smells that seem foreign and dangerous in a highly-marketised world to re-enact the performativity of our collective interpretation of 'deviance' (Blackshaw and Crabbe 2004). While they assume that Others generally avoid the moudly scents of filth and the pungent mustiness of abandoned sites, 'the Boyz' create their own inimitable space around these smells, insofar as there is some degree of pride and gratification associated with being linked to them. From a Husserlian perspective, it could be suggested that 'the Boyz' effectively perform, pre- 
reflectively, what is known as an 'exclusive disjunction' (Husserl 1973: 57), meaning they notice not the fetidity of stagnant disease-filled rot, only the sign that there is a smell of 'urbex' and 'the Boyz' in the air. According to Husserlian doctrine, only one or the other can be perceived, never both together. Therefore, following Husserl's treatment of reason, it could be argued that a bad smell is not necessarily bad de facto in present modernity. Rather, in line with the idea of 'transcendental subjectivity' it can be argued that we assign every object, or in this instance smell, determinate attributes (temporarily at least) which cancel out all others (Merleau-Ponty 1989), including all concern with danger, disease and mortality.

Yet, irrespective of anyone's skill in their writing, or their verbal facility, when it comes to describing or explaining any olfactory system of leisure what 'the Boyz' create for themselves represents a radically different existential possibility that cannot quite be grasped by any outsider. Following what Ackerman (1995) has suggested, despite our remarkable ability to connect certain smells with events and other people it is impossible to describe them accurately to anyone who has not smelled them or experienced them in precisely the same way as a group such as 'the Boyz'. In one sense, this is the beauty of leisure worlds and shared performative identities. However, what is also crucial, as Ackerman (1995) points out, is that out of context scents like those rotting and musty odours that go together with 'the Boyz' unique social space can become a source of embarrassment because back in the space of everyday reality they produce starkly different connotations.

\subsection{Secretions of Poverty}

Following the last point, a third paradoxical theme remains to be discussed and it is another Corbin raises in his book - the anxiety surrounding 'secretions of poverty' (1986: 142). Since the rise of the bourgeoisie, which brought with it the need to project onto the poverty-stricken everything that ought to be repressed (including bad odours), it has become the general masses who keep alive the smells of degeneracy, animalism and moral stigmatisation (Tuzin 2006; Classen et al. 1994; Largey and Watson 1972). The unpleasant stench of an-Other more miserable life strikes fear into the minds of the masses and the risk of contagion makes us squirm uncomfortably (Corbin 1986). As Bauman (1998) reminds us, alongside certain ethnic and minority groups, vagrants and the dispossessed are quintessential examples of the 'abnormal', 'strange' and 'out-ofplace'; they are individuals of suffering and disenchantment who are fated to show the rest of society what happens if we become 'flawed' consumers. In short, it is not as George Orwell famously put it that 'the lower classes smell' (1962: 127-128), the point, as Bauman (1998) explicates, is that it has now become possible to fall beneath the so-called ranks of the classes where odours are even more repulsive. However, it seems the performative identity 'the Boyz' seek is, in essence, at loggerheads with the type of modernity we find ourselves in.

On the one level, the repulsive odour of the stricken, the dirty rags their bodies are clad in, and their apparent failure to notice the inconvenience of the miasma is a reminder to 'the Boyz' that we can easily become one of those odourous individuals and, therefore, be excluded from the common appearance of order. As MKD demonstrated on the ferry, he was suddenly very conscious of our ragged clothing and the smells oozing from us. He was right too, there was a nauseating odour clinging to us 
all; the overpowering, greasy, tang of sweat caught in our tangled facial hair, the whiff of stale body odour when any of us shifted position, and the bitter-sweet sting of our unclean breath when we spoke. As MKD put it, 'I feel really outta place, like. People'll think we homeless or some fuckin' scummy dole munchas', like.' There was no doubt about it, we were raising a few eyebrows, and while most of the tables around us were full, the three closest to us remained empty for the duration of our crossing. The anxiety among 'the Boyz' gradually became more noticeable and seemed to reach its height when Soul decided to point out that our mud-caked footwear absolutely stank of 'cow shit'. After that, a couple of 'the Boyz', including myself, went to the nearest toilet to clean up a little - at this point we really wanted to blend back in with the other consumers on board the ferry. As MKD revealed on the final leg of our journey up the A1(M), 'stinkin' of fuckin' shit really puts me off cummin' on these trips. Pisses me right off, man...'.

Whether we like it or not, present modernity engages us all as consumers where certain fragrances rank higher than others (Classen et al. 1994). What this means is that to be part of the social norm, to be assured of our membership, 'the Boyz' need to respond 'promptly and efficiently to the temptations of the consumer market; [we] need to contribute to the supply-clearing demand and in case of economic trouble be part of the consumer-led recovery' (Bauman 2005: 112). It is vital, therefore, that 'the Boyz' engage in 'active somatic surveillance' to identify which odours convey good social impressions and isolate those that violate the moral and aesthetic 'rituals' of everyday consumer life (Waskul and Vannini 2008). None of this is possible, though, if we fall victim to what Günther Anders refers to as 'Promethean shame'; the shame of not fulfilling our duty to be reflexive and aesthetically olfactic and, on the whole, more effective consumers (Müller and Anders 2016). As Bauman puts it:

Members of the society of consumers are themselves consumer commodities, and it is the quality of being a consumer commodity that makes them bona fide members of that society. Becoming and remaining a sellable commodity is the most potent motive of consumer concerns, even if it is usually latent and seldom conscious, let alone explicitly declared (Bauman 2007b: 57).

In the episode above, 'the Boyz' no longer felt the warm homeliness of being a consumer. Instead, there was a sense of homelessness in the atmosphere, and the anxiety and apprehension that comes with realising how easy it is to stumble across the boundary that separates the dreams and desires of the 'tourist' mindset from that of the corrupt, underprivileged, 'vagabond' (Davis 2008).

On the other hand, as it was touched upon earlier in the article, irrespective of consumerist aestheticism 'the Boyz' have found something dirty and foul they want to consume. What this means is that there is still something about those dank spaces, those spaces which exude foul odours and arouse peculiar feelings inside us, that makes us want to seek them out. At this stage in the article, then, it would be more appropriate to refer to the type of leisure we are dealing with here, which encompasses all of the enigmatic performative behaviour that was mentioned previously, as 'heterotopic leisure' (Blackshaw 2017a). This draws on the work of Michel Foucault (1984) which introduces us to the idea of heterotopias of deviance; those spaces of 'compensation' that permit people to imaginatively discover their own unique place in reality. As 
Blackshaw notes, underneath the smooth surface of everyday life heterotopias provide a temporary 'feast for anyone hungry for otherness' (2017b: 7). They represent an uncanny desire for a different sort of knowledge and a special sense of freedom and performativity that cannot be obtained in the same way anywhere else. In other words, the heterotopia 'the Boyz' create for themselves comprises an alternative, what we might call compensatory, type of cognitive, aesthetic and moral space where different life strategies and ways of interpreting the world are employed (Bauman 1993b).

What this reinforces is that in present modernity there is more to heterotopic (and 'deviant' and 'abnormal') forms of leisure than commonsensical understandings of deviancy would have us believe, because they provide people, specifically consumers, with opportunities to safely transgress the border between the permissible and what is, ostensibly, forbidden (Blackshaw 2017a). For Rojek (2000), this sort of leisure transforms people into self-proclaimed connoisseurs of thrills, 'deviance' and the offensive, especially of the olfactory kind when it comes to urban exploration. Looking forward to the smell of decay, as Mayhem and Husky discussed in the boat with eagerness, and to arrive back in society stinking of corruption and putrefaction, and initially feeling proud of it, is to feel inimitable and cool. Nonetheless, this is, on the face of it, a special coolness that is at odds with the idea of commercialised coolness we find in contemporary culture. As Pountain and Robins (2000) point out, the 'coolest' have always had a habit of trying to distinguish themselves as such by declaring themselves as pioneers of new trends. However, it could be suggested that by striving to become dirty, malodourous, vagabonds, 'the Boyz' in fact try to become more 'cool' than 'cool' by becoming 'uncool', because while everyone has access to it the idea of 'cool' cannot help but be empty (Heath and Potter 2006). As Blackshaw puts it, 'it is the vicarious sense of having done something bad that feels rather cool that matters' (2017b: 6), and, as 'the Boyz' have discovered, it is within heterotopia where this becomes possible, for a while.

To rein back in on the olfactory system, as far as 'the Boyz' are concerned their heterotopia is a place of expression, identity and freedom that is created, in part, by mingling closely with the foul and the foetid. In other words, this is where the second level of olfaction comes into play, where the foulness of pigeon shit and the fetidity of decay are transformed by a certain poetics of putrefaction that incites powerful feelings of nostalgia and fear. What this means is that when it comes to 'the Boyz' heterotopic social space bad smells - bad in the everyday sense at least - remind them not only of their inimitability and 'coolness' but also the magnificent sense of purpose, pleasure and passion they have felt as a result of it. In 'the Boyz' heterotopia the smell of something putrid in the air is a sign that a different 'taste' of life is being experienced and, more often than not, they promise themselves that they will endeavour to smell their way into such experiences again. With this in mind, the final section of this article goes on to unpack the second level of olfaction a little further.

\section{Poetics of Putrefaction: The Smell of Nostalgia, Fear and Melancholy}

According to Ackerman (1995), although the olfactory system has traditionally been used to detect danger and stimulate healing or aphrodisiac qualities, it has become recognisable as the sense that is less intimate and intense than all other senses and, 
therefore, less important. In 'liquid' modernity it is, as Bauman (1993a) reminds us, nothing more than something that should be managed. Yet, if one thing has been overlooked, as it has been brought to light throughout this paper, it is that there is a second level to olfaction in that poignant smells act like powerful cataracts to stimulate emotions and former memories that link directly to the performativity of heterotopic social spaces (Bonnett 2016). In other words, when it comes to leisure it can be argued that smells are important because our memory is able to transform those all-too-familiar scents into a 'collective task of interpretation which is... ineradicably yoked by a romantic sensibility that evokes feelings of nostalgia' (Blackshaw 2013: 75; Waskul and Vannini 2008; Stoller 1997).

Drawing on Tony Blackshaw's (2003) concept of the mundane and the spectacular, the following section of this article attempts to unpack the nostalgic significance of the olfactory system vis-à-vis 'the Boyz' heterotopic social space that has been formed through the medium of urban exploration. At this stage, then, it should be noted that the mundane and spectacular aspects of heterotopia comprise much more than the olfactory sense, but what is being developed here is a more lucid understanding of how smells contribute to the creation of leisure worlds that function as temporary performative refuges. ${ }^{4}$

\subsection{The Mundane}

As Blackshaw (2003) explicates, the mundane is centred around the 'great truths' of 'the Boyz' heterotopic world; therefore, alongside a particular ritualised routine it is the smells of what they imagine as being commonplace and mundane that are also relived. As the heterotopia typically begins, then, 'the Boyz' scramble into a well-used car, which is usually Mayhem's. It is imbued with a strange yet communally satisfying odour. A fresh, sweet-smelling, almost earthy scent that is instantly pleasant to the imagination, mixed with the stale, skunk-like, sour stench of old marijuana, harsh musky sweat aromas engrained in the fabric of the car seats and whatever chemicalenriched air freshener is dangling from the mirror. If ever there was a person who wanted to imagine the odour of one large sweat gland this would probably be it. Once inside the car, the mundane circumstances continue as the journey to an abandoned building, drain or some other explore begins. Husky will open his grinder to roll a fresh spliff, revitalising the strong conspicuous smell of burning hemp rope. This odour mixes with the slightly dusty smell of rich overripe fruit as cans of beer and cider are cracked open in the back of the car. The wonderful sense-drenching odour of the car is likely to sound foul to any outsider, yet for 'the Boyz' it is a sign that the mystical aromas of the heterotopia have sprung to life.

The mundanity of the olfactory system does not end there either, it continues as the exploring truly gets underway. Before 'the Boyz' even enter an abandoned site, a certain craved-for odour can be detected. It is difficult to describe, but Soul has suggested it is 'a woody aroma, tinged with that amazing plastery dust smell. Like decaying concrete...' For MKD, 'it's a smell a bit like when you turn a heata' on fur the first time, just without any heat, but nice. It's nicer, like a smell of a familiar place cos

\footnotetext{
${ }^{4}$ For further reading, Tony Blackshaw's book Leisure Life deals with his concept of the mundane and spectacular in greater depth.
} 
it's always the same.' Mayhem often describes it as being 'a dusty toned-down equivalent of rosemary, or camphor... but without much sweetness or spice. Like, like, delicious mothballs, maybe?' Nonetheless, according to 'the Boyz' if any of them have captured the mundane olfactory essence of their heterotopic world it is Husky and his description of it being 'familia'. Like, a cumfurtable warm damp-nss. Like, rank and propa' fuckin' stale. Probably disgusting, but as if these places are also oozing this amazin', like really satisfying sort of damp brick, an earthy kind of smell that you want to chew.' As the reader might agree, then, out of all 'the Boyz' it is perhaps Husky who really captures the strange oxymoronic mundanity of the heterotopia.

To draw once again on an important point that was raised earlier, it is clear that when it comes to the mundane aspects of their heterotopia what 'the Boyz' are demonstrating is their ability to perform an exclusive disjunction. This means odours that are not normally sought after in everyday life can become emblematic of an inimitable collective heterotopia that has been built around a particular form of leisure (Husserl 1973). In other words, because smells can be overpoweringly nostalgic and homely they seem to elicit intense emotions and representations that remain largely unedited or altered (Ackerman 1995). As Edwin Morris points out, while the things you hear and observe may be prone to disappearing in the compost heap that we refer to as our shortterm memory, 'there is almost no short-term memory with odours' (1984: 44). In view of this, it is the incredible homeliness of mundanity, especially the smell of that mundanity, that is part and parcel of 'the Boyz' heterotopic social space that assures us we are back together (Blackshaw 2017a). It can be argued, therefore, that certain odours stimulate our imaginations and work to intensify our warm sense of unity (Morris 1984). For example, the typical mundane scent of the abandoned farmhouse teased us, more so as it amalgamated with the all-too-familiar odours of our beer, smoke, food and our well-used belongings, effectively isolating us, but also reinforcing our proverbial memory of freedom, escape and the knowledge that we are able to shapeshift into a seemingly secure performative identity that has no place anywhere else (Foucault 1984; Blackshaw 2017a).

\subsection{The Spectacular}

In addition to the mundane aspects of heterotopia, there are, according to Blackshaw (2003), sporadic instances where leisure worlds can become spectacular; it might well be argued that this is the point at which the performativity of 'the Boyz' becomes most powerful and compelling. In other words, as Blackshaw explicates, the spectacular is what creates an intensity that is even more superior (far more so than the mundane) when it comes to our sense of belonging (ibid). What this means vis-à-vis the senses is that there may be some smells that have a more profound magical charm, and that they are capable of resurrecting past memories and ontological feelings that elicit greater nostalgic power. As Corbin argues, 'like voyeurism, some olfactory behaviour patterns permit a new conduct of the rhythms of desire' (1986: 207). To put it concisely, such smells are intoxicatingly nostalgic.

As the reader witnessed in the opening episode, when the 'Boyz' started to cross the putrid moat, the rich odours of staleness and of sweet decay coalesced with our growing fear and excitement. Paddling with one paddle and getting caught in thick overhanging branches severely affected the stability of the boat, causing foul water to spill over the 
sides and onto our clothes. We were terrified of capsizing, of being forced to swim in the filth, but unbelievably energised by the chaos of the situation and the incredible provocation of our nostrils. Soul's cries of elation and terror at the time work well to expound on the moment in a little more detail, when none of us were quite sure whether to laugh or panic every time the boat rocked violently:

'Waaaa... Oooaaahhh... Fuck! Fuck! Fuck! Stop fucking leanin'. Guys, Jesus. Fuck, fuck, we're gonna fall in that shit.... [There is a tone of panic in his voice, but he begins to laugh hysterically. This sets off the others]. Jesus Christ, man, what the fuck are we doing?'... [Laughing uncontrollably]. It stinks and I can't even swim. [More intense laughter]... Woah! Stop! You're fucking splashing us, man... It reeks. Fuck! I bet we smell of this shit now.'

The penetrating odours of the spectacular moment in our heterotopia did not end on the moat either, they continued inside the castle. In this moment, actually within the walls of the stronghold, all the rules and smells of the everyday were pushed aside to allow the promiscuity and entrancing feelings of the spectacular to take over completely. It was there, fully embracing the odour of the castle, that signified the epitome of 'the Boyz' heterotopia where our performativity - being 'deviant', dirty, urban explorers was, in one word, supreme.

To draw once again on Simmel's (2014 [1890]) point about hyperaesthesia that was introduced earlier in this article, what is being demonstrated is that 'the Boyz' are exercising their craving for an excessive stimulation of their olfactory senses as they try to ignite what might be described as a sublime moment (Lyotard 2006). As Lyotard would argue, it is the erratic, ephemeral, pace of the unrepresentable that 'the Boyz' seek. It can be suggested, therefore, that the smells of abandonment and decay, together with the tangible experience of exploring itself, work well to satisfy this craving because they are so unmasterably complex and inexpressible. The sublime is, after all, something that tempts us because it bears its foundations in any situation capable of stirring, simultaneously, the extremes of pleasure and pain (or fear). For this reason, it is something many of us have a raging thirst for (Burke 2008 [1729]; Lyotard 2006). This is the beauty of heterotopic social spaces - on top of inflaming our other senses they allow us to smell something so exciting and disturbing it provokes violent emotions that cannot be found elsewhere (Lyotard 2006). It is this deep sense of pleasure and displeasure that makes us fiercely nostalgic and desire strange odours all over again, to the extent that we are willing to hunt for them in those foul, foetid, places most people want to avoid.

Notwithstanding the importance of the points raised so far in this section, there is yet another aspect of smell and nostalgia that has up until now remained unexplored. What follows, then, is a brief consideration of Bauman's (1991) argument that present modernity has evolved into a 'never-drying' age of anxiety, irrationality, undecidability and confusion. What this means is that in their attempt to preserve a sense of existential certainty and ontological security, 'the Boyz' inevitably find themselves forced to create a performative world that cannot help but encompass certain undesirable elements which could be referred to as the melancholic side of heterotopia. 


\subsection{The Melancholic}

After experiencing 'the Boyz' heterotopic social space first-hand, I would argue that a Freudian perspective could be adopted to draw out the point that Eros (the pleasure instinct) and Thanatos (the death instinct) are in a constant struggle against one another. As Freud (2008 [1963]) argues, the latter naturally seeks to destroy the former and this is perhaps achieved when the intensity of foul and the foetid becomes too intense, insofar as the mundane smells of the heterotopia rapidly break down and start to destroy themselves. To put it another way, it can be argued that any leisure-based group or collective, especially when smells are exploited or involved as they are in urban exploration, can lead to the production of a leisure world where desires reach their absolute limit, or perhaps fall significantly short of the mark, and cannot be exceeded (ibid). When this happens melancholia takes over which, according to Freud, is governed 'silently' and 'elusively' by the Nirvana Principle (a forceful yearning for a state of oblivion). This so-called compulsion perhaps signals that the permanent end to the heterotopia is in sight and it brings with it a peculiar, almost inexplicable, urge to suddenly tear it apart and extinguish it for good (ibid).

To elaborate further, by the end of our trip the heterotopia appeared to be wavering. Sat in the car just south of London, dwelling miserably on the overwhelming stench of our own sweat and grotty filth, it was obvious that the mood had transformed. 'The Boyz', but most especially Husky, seemed eager to get home; the smell and constant feel of being dirty was 'doin' [their] 'eads in.' To reiterate a point made earlier, as MKD put it, 'stinkin' of fuckin' shit really puts me off cummin' on these trips. Pisses me right off, man...'. In other words, we were struggling to contain our annoyance and frustration. Mayhem also summed up how we were all feeling and, on this occasion, was the one to repeat something many of us have said in the past: 'This is the last time I'm doin' this. I think I'm done with this fuckin' shit. My car stinks! It's gonna smell like this for days now. It always makes me feel sick afterwards, like whenever I get inside 'ere.'

Nonetheless, what has been overlooked is the notion that in the dialectical interplay between the life instincts Eros and Thanatos, the urge to reproduce and recreate tends to rematerialise, insofar as Eros 'somehow binds Thanatos to its own ends' (Cutrofello 2005: 129). What this means is that we can look more positively, and indeed optimistically, at the melancholic aspect of 'the Boyz' heterotopia because it is also, as Blackshaw (2013) suggests, that feeling we get when we want to protect ourselves against the loss of something important.

As Freud's (1995 [1917]) theory of melancholy portends, to preserve a sense of existential certainty and ontological security individuals who enter the melancholic aspect of their heterotopic social space can attempt to exploit the feeling of loss into the eventual reconstruction of their heterotopic social space. ${ }^{5}$ In other words, it can be argued that in due course, whether it is a few hours, days or weeks after the heterotopia came crashing to an abrupt end, 'the Boyz' mourn the loss of the familiar smells

\footnotetext{
${ }^{5}$ It is important to make the point that each time heterotopic social space materialises it is still its own unique event, a fantasy that is nothing more and nothing less than the performativity that injects life into it (see Blackshaw 2017a, b). In other words, the reconstruction of the heterotopia - and its mundanity, spectacularity and melancholia - is never quite the same each time but it feels just-as-good-as the last time, and just-as-goodas the time before that.
} 
associated with their special world; in their collective memory those smells become strangely nostalgic and are transformed into something that feels warm and homely two things that are becoming ever more difficult to locate in present modernity (Blackshaw 2017a). In the end, the melancholic aspect of their heterotopia makes 'the Boyz' realise that beyond the unsatisfactoriness of the everyday world they have a sense of place that, along with everything else, brings with it its own fantastical odours that are unlike anything they experience in any other area of their lives. There is, however, a certain impossibility when it comes to satisfying melancholy; whatever is reconstructed cannot last because it is only ever temporary. What this means, therefore, is that the melancholic aspect of heterotopia may find itself being repeated time and time again (Freud 1995 [1917]).

As 'the Boyz' reveal, then, together their central aim is to rekindle a heterotopic social space built around the all-too-familiar sights, physical sensations, sounds, tastes and, above all, the smells of their performativity and impression of urban exploration that produce something far superior to anything likely to be found in the everyday. Yet, to reign back in exclusively on odour once more, what this means is that while living for the moment brings with it smells that stimulate incredible feelings of homeliness and ecstasy, it also brings along smells that reminds us of its contingency and indeterminateness. It can be argued, therefore, that unpacking the foul and the fragrant aspects (the poetics of putrefaction) of a particular heterotopic social space reveals more about the transient and random acts of social memory which is, at the base of things, an active process rather than a passive one that exploits mundanity, spectacularity and melancholia.

\section{Summary}

What the forgoing discussion has suggested is that olfaction is something that is generally overlooked when it comes to leisure studies, especially when dealing with forms of 'deviant', 'abnormal' or, as it has been referred to it in this paper, 'heterotopic' leisure such as urban exploration. It might be described, therefore, as the rejected and excluded sense, and in the eyes of many observers represents the residual side of progress. However, as I have argued, when it comes to understanding and indeed forming interpretations about certain forms of leisure the sense of smell is valuable because it exposes some of the key features of present modernity.

Using the seminal work of Alain Corbin (1986) as a starting point, this paper began by unpacking the odours which can be attributed to, and in some cases produced by, a group of urban explorers who are known collectively as WildBoyz. The aim in the first half of the paper was to identify how olfactory sensations continue to influence behaviours, habits and social perceptions in the same way they always have throughout modernity. What has been revealed is that smells, namely those that are identified as being foul and foetid, have always had a frictious relationship with modernity and that, in many ways, little has changed. Such smells have for a very long time had a close affinity with the history of fear, disgust, poverty and the powerful compulsion to purify and disinfect.

However, beyond the anxiety, repugnance and general intolerance miasma can cause, for people like 'the Boyz' there is a second level to the olfactory system, one 
that operates on the other side of modernity through leisure and a certain poetics of putrefaction. In other words, as prolific thinkers such as Zygmunt Bauman and Tony Blackshaw remind us, modernity has reached a stage in its evolution where people have never before experienced such freedom to be performative as it has become a breeding ground for heterotopias of deviation. Given that heterotopias are only temporary, though, and encompass certain people and things so dissimilar to what we find in the everyday world, like the smells of rot, decay and sweat mingled with cheap beer and weed, they provide a stage for inciting the inexplicably magical and equally painful feelings of nostalgia as recurrences of such leisure experiences are craved for.

The final section of this paper went on to unpack the nostalgic significance of smell vis-à-vis 'the Boyz' heterotopic social space. It was suggested that certain smells stimulate emotions and memories to recreate a temporary compensatory space that feels both magically homely and exciting. Following Blackshaw's (2003) concept of the of the mundane and spectacular and my own appendage of the melancholic, it was argued that there are certain odours that are part and parcel of the 'great truths' of 'the Boyz' heterotopic world, others that provoke feelings and memories that are truly magnificent, and some that threaten to fracture and destroy (but not quite) the whole performative world and the imagination behind it. In a nutshell, what this tells us is that individuals can use certain forms of leisure to smell their way to freedom. To elaborate, if we thought there were infinite sources of self-expression and eccentricity within reach thanks to our so-called 'higher' senses, what we have learned by looking at 'the Boyz' is that the olfactory system supplies us with even more ways of interpreting leisure that are different, inventive and as Foucault might have put it himself, bad and almost certainly a little bit mad.

Open Access This article is distributed under the terms of the Creative Commons Attribution 4.0 International License (http://creativecommons.org/licenses/by/4.0/), which permits unrestricted use, distribution, and reproduction in any medium, provided you give appropriate credit to the original author(s) and the source, provide a link to the Creative Commons license, and indicate if changes were made.

\section{References}

Ackerman, D. (1995). A natural history of the senses. New York: Vintage Books.

Bauman, Z. (1989). Modernity and the holocaust. Cambridge: Polity Press.

Bauman, Z. (1991). Modernity and ambivalence. Cambridge: Polity Press.

Bauman, Z. (1992). Mortality, immortality and other life strategies. Stanford, California: Standford University Press.

Bauman, Z. (1993a). The sweet scent of decomposition. In C. Rojek \& B. S. Turner (Eds.), Forget Baudrillard? (pp. 22-46). London: Routledge.

Bauman, Z. (1993b). Postmodern ethics. Oxford: Blackwell Publishing.

Bauman, Z. (1998). Globalization: The human consequences. Cambridge: Polity Press.

Bauman, Z. (2000). Liquid modernity. Cambridge: Polity Press.

Bauman, Z. (2005). Work, consumerism and the new poor. Maidenhead: Open University Press.

Bauman, Z. (2007a). Liquid Times. Cambridge: Polity Press.

Bauman, Z. (2007b). Consuming life. Cambridge: Polity Press.

Berger, J. (1972). Ways of seeing. Harmondsworth: Penguin.

Blackshaw, T. (2003). Leisure life: Myth, masculinity and modernity. London: Routledge.

Blackshaw, T. (2013). Working-class life in northern England 1945-2010: The pre-history and after-life of the Inbetweener generation. Basingstoke: Palgrave Macmillan. 
Blackshaw, T. (2017a). Re-Imagining Leisure Studies. Oxon: Routledge.

Blackshaw, T. (2017b). Some notes on the language game of dark leisure. Annals of Leisure Research., 20(5), 1-12.

Blackshaw, T., \& Crabbe, T. (2004). New perspectives on sport and deviance: Consumption, performativity and social control. Oxfordshire: Routledge.

Bonnett, A. (2016). The geography of nostalgia: Global and local perspectives on modernity and loss. Oxon: Routledge.

Burke, E. (2008 [1769]). A philosophical enquiry into the sublime and beautiful. Oxon: Routledge.

Classen, C., Howes, D., \& Synnott, A. (1994). The cultural history of smell. London: Routledge.

Corbin, A. (1986). The foul and the fragrant: Odor and the French social imagination. Leamington Spa: Berg Publishers Ltd..

Cutrofello, A. (2005). Continental philosophy: A contemporary introduction. Oxon: Routledge.

Davis, M. (2008). Bauman on globalization - The human consequences of a liquid world. In M. H. Jacobsen \& P. Poder's (Eds.), The sociology of Zygmunt Bauman: Challenges and critiques (pp. 137-154). Oxon: Routledge.

Derrida, J. (1993). Memoirs of the blind: The self-portrait and other ruins. Chicago: Chicago University Press.

Elias, N. (1994). The civilizing process: The history of manners and state-formation and civilization. Oxford: Blackwell.

Foucault, M. (1970). The order of things: An archaeology of the human sciences. London: Tavistock Publications Limited.

Foucault, M. (1984). Of other spaces. Trans. J. Miskowiec. Diacritics., 16(1), 22-27.

Foucault, M. (2003). The birth of social medicine. In P. Rabinow \& N. Rose (Eds.), The essential Foucault (pp. 319-337). New York: The New Press.

Foucault, M. (2004). The crisis of medicine or the crisis of Antimedicine. Trans. E. C. Knowlton. Foucault Studies, 1, 5-19.

Freud, S. (1994). Civilization and its discontents. Trans. J. Riviere. New York: Dover Publications, Inc..

Freud, S. (1995 [1917]). Mourning and melancholy. In: P. Gay (Ed), The Freud reader. London: Vintage.

Freud, S. (2008 [1963]). General psychological theory: Papers on metapsychology. New York: Touchstone.

Heath, J., \& Potter, A. (2006). The rebel sell: Why the culture can't be jammed. Chichester: Capstone Publishing Ltd..

Hockey, J. (2006). Sensing the run: The senses and distance running. Sense and Society., 1(2), 183-202.

Howes, D. (2005). Empire of the senses: The sensual culture reader. Oxford: Berg.

Husserl, E. (1973). Cartesian meditations: An introduction to phenomenology. Trans. D. Cairns. The Hague: Martinus Nijhoff.

Kant, I. (1974). Anthropology from a pragmatic point of view. Trans. M. J. Gregor. The Hague: Martinus Nijhoff.

Largey, G., \& Watson, D. R. (1972). The sociology of Odours. American Journal of Sociology., 77, 1021-1034.

Lashua, B., \& Kelly, J. (2008). Rhythms in the concrete: Re-imagining relationships between space, race, and mediated urban youth cultures. Leisure/Loisir., 32(2), 461-487.

Low, K. (2009). Scents and scent-sibilities: Smell and everyday life experiences. Newcastle upon Tyne: Cambridge Scholars Publishing.

Lyotard, J.-F. (2006). The communication of sublime feeling. In K. Crome \& J. Williams (Eds.), The Lyotard Reader and Guide. New York: Colombia University Press.

Martin, G., \& Triplett, K. (2013). Purification: Religious transformations of body and mind. London: Bloomsbury.

Merleau-Ponty, M. (1989). Phenomenology of perception. London: Macmillan.

Morris, E. (1984). Fragrance: The story of perfume from Cleopatra to Chanel. New York: Schribner.

Müller, C. J., \& Anders, G. (2016). Prometheanism technology, digital culture and human obsolescence. London: Rowman \& Littlefield International.

Orwell, G. (1962). The road to Wigan pier. London: Penguin Books Ltd..

Pountain, D., \& Robins, D. (2000). Cool rules: Anatomy of an attitude. London: Reaktion Books Ltd..

Rojek, C. (1995). Decentring leisure: Rethinking leisure theory. London: Sage Publications.

Rojek, C. (2000). Leisure and culture. Basingstoke: Palgrave Macmillan.

Rorty, R. (1979). Philosophy and the Mirror of nature. Oxford: Blackwell.

Simmel, G. (1890 [2014]). On art exhibitions. Theory, Culture \& Society. 32 (1): 87-92.

Sparkes, A. (2009). Ethnography and the senses: Challenges and possibilities. Qualitative Research in Sport and Exercise., 1(1), 21-35.

Spracklen, K., \& Spracklen, B. (2014). The strange and spooky battle over bats and black dresses: The commodification of Whitby goth weekend and the loss of a subculture. Tourist Studies., 14(1), 86-102.

Stoller, P. (1997). Sensuous scholarship. Philadelphia: University of Pennsylvania Press. 
Swain, S., Spracklen, K., \& Lashua, B. (2018). Khat-chewing in liminal leisure spaces: British-Somali youth on the margins. Leisure Studies., 37(4), 440-451.

Synnott, A. (1991). A sociology of smell. Canadian Review of Sociology., 28(4), 437-459.

Tuzin, D. (2006). Base notes: Odor, breath, and moral contagion in Ilahita. In: J. Drobnick (Ed), Smell Culture Reader, 23-44.

Virilio, P. (1977 [2006]). Speed and politics. Trans. M. Polizzotti. Los Angeles: Semiotext(e).

Wacquant, L. (2006). Body and soul: Notebooks of an apprentice boxer. New York: Oxford University Press. Waskul, D., \& Vannini, P. (2008). Smell, odor, and somatic work: Sense-making and sensory management. Social Psychology Quarterly., 71(1), 53-71.

Publisher's Note Springer Nature remains neutral with regard to jurisdictional claims in published maps and institutional affiliations. 